\title{
Evaluation of Newly Synthesized Chalcone \\ Derivatives Effect on PC12 Cells in in Vitro Model of The Parkinson's Disease As a Potential Treatment
}

Mona Farhadi

Islamic Azad University

Zahra Sanadgol

Islamic Azad University

Seyed Behnamedin Jameie

Iran University of Medical Sciences

Elmira Kashani

Tabriz University of Medical Sciences

Nader Noroozi Pesyan

Urmia University

Roshanak Kian

University of Tabriz

Shahla Golghasemi Sorkhabi ( $\sim$ Shahla.golghasemi@gmail.com )

University of Tabriz

Amir Nasser Shamkhali

University of Mohaghegh Ardabili

Mohammad Sadegh Zakerhamidi

University of Tabriz

\section{Research Article}

Keywords: Newly Synthesized Chalcone Compound, Oxidative Stress, Apoptosis, Antioxidants, PC12 Cells, Parkinson's Cell Model, 6-hydroxydopamine, Interactional Characterization

Posted Date: April 1st, 2021

DOl: https://doi.org/10.21203/rs.3.rs-354679/v1

License: (c) (1) This work is licensed under a Creative Commons Attribution 4.0 International License.

Read Full License 


\title{
Evaluation of Newly Synthesized Chalcone Derivatives effect on
}

\section{PC12 Cells in in vitro model of the Parkinson's disease as a potential}

\section{Treatment}

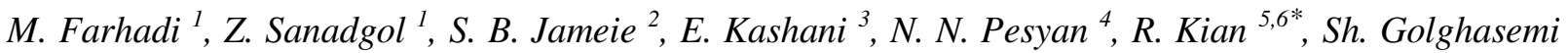 \\ Sorkhabi $^{6,7}$, A.N. Shamkhali ${ }^{2,8}$, M.S. Zakerhamidi ${ }^{5,6}$ \\ ${ }^{1}$ Department of Microbiology, Karaj Branch, Islamic Azad University, Karaj, Iran \\ ${ }^{2}$ Neuroscience Research Center (NRC), Iran University of Medical Sciences, Tehran, Iran, \\ ${ }^{3}$ Department of Medical Nanotechnology, Faculty of Advanced Medical Sciences, Tabriz University of Medical Sciences, \\ Tabriz, Iran \\ ${ }^{4}$ Department of Organic Chemistry, Faculty of Chemistry, Urmia University, Urmia, 57159, Iran \\ ${ }^{5}$ Department of Physics, University of Tabriz, Tabriz, Iran \\ ${ }^{6}$ Research Institute for Applied Physics and Astronomy (RIAPA), University of Tabriz, Tabriz, Iran \\ ${ }^{7}$ University of Angers MOLTECH-Anjou (UMR6200), Univ. Angers, CNRS, F-49045 Angers, France \\ ${ }^{8}$ Department of Chemistry, Faculty of Sciences, University of Mohaghegh Ardabili, Ardabil, Iran
}

KEYWORDS. Newly Synthesized Chalcone Compound, Oxidative Stress, Apoptosis, Antioxidants, PC12 Cells, Parkinson's Cell Model, 6-hydroxydopamine, Interactional Characterization

Corresponding Authors:

\section{* Shahla Golghasemi Sorkhabi,}

Research Institute for Applied Physics and Astronomy (RIAPA), University of Tabriz, Tabriz, Iran, Tel: +989147702135 ,

University of Angers MOLTECH-Anjou (UMR6200), Univ. Angers, CNRS, F-49045 Angers, France, Email: Shahla.Golghasemi@gmail.com

\section{* Roshanak Kian,}

Research Institute for Applied Physics and Astronomy (RIAPA), University of Tabriz, Tabriz, Department of Physics, University of Tabriz, Tabriz, Iran

Iran, Email: Roshanak_kian@tabrizu.ac.ir 


\section{ABSTRACT:}

Chalcone is a common simple scaffold found in many naturally occurring compounds. Many Chalcone derivatives have also been prepared due to their convenient synthesis. These natural products and synthetic compounds have shown numerous interesting biological activities, such as antioxidant, anti-inflammatory, induction of apoptosis, and angiogenesis. As the second most common neurodegenerative disease after Alzheimer's disease, Parkinson's disease is most common motor function disorder. Even though this disease is not fully understood, processes such as oxidative stress and neuronal apoptosis are largely involved in its progress. As such, antioxidants are significant agents in slowing down the process through running interference in ROS production and apoptosis. Here, we present the effect of three newly synthesized Chalcone compounds on 6-OHDA-induced cytotoxicity on the PC12 cells in Parkinson's disease model by integrating several experimental (MTT assay, ROS assay, Annexin \& PI assay, Western blotting P53, Bax, Bcl2) data and validating the results based on the interactional contribution equations of these compounds obtained from previous experimental and theoretical study carried out on the molecular resonance and interactional behavior of these compounds via Linear solvation energy relationship (LSER) model and time-dependent density functional theory and configuration interaction calculations. We conclude that all three Chalcones have neuroprotective activity, and presented a reduction in ROS production and an increment in cell viability in the groups treated with 6-OHDA. This effect was observed at lower concentrations for all Chalcone compounds. At higher concentrations Chalcones 1 and 2 showed cytotoxicity. However, Chalcone 3 did not show any cytotoxicity, even for high doses, which points out the therapeutic potential of this Chalcone in reducing the dopaminergic cell destruction. 


\section{Introduction}

In the year 1817, James Parkinson, presented the detailed description of the Parkinson's disease symptoms and named the disease "Shaking palsy". Parkinson's disease (PD) is the second most common neurodegenerative disease after Alzheimer's disease, which is resulted from the death of cells in the substantia nigra, a region of the midbrain, leading to a dopamine deficit [1], [2]. The cause of this cell death is poorly understood but the most obvious symptoms are resting tremor, bradykinesia, postural instability, and also cognitive and behavioral problems [3], [4].

The prevalence rate of Parkinson's in people over 50 years old has been reported at approximately $2 \%$. The reactive oxygen species, such as anion superoxide, hydroxyl radicals, and hydrogen peroxide, created as the by-products during the metabolism process of oxygen, are some of the most important causes of neuronal damage. Oxidative stress-induced apoptosis is a prominent feature of age-related neurodegenerative diseases [5]-[7].

To study the molecular mechanism and the behavioral and pathological variations of this heterogeneity a variety of animal models is required, to better understand the different aspects of the disease. Three main approaches are used to model PD in experimental animals: genetics [8], viral models [9], and neurotoxins [10]-[12]. The latter, as the easiest and the less expensive method, is the mostly used technique for researchers. 6-hydroxydopamine (6-OHDA) is one of the most widely used neurotoxic compounds that can regenerate oxidative stress, neurodegeneration, neuroinflammation, and cell death; as some of PD's main cellular processes in animal models [13], [14]. To this day, there are three reported mechanisms to explain the cytotoxicity of 6-OHDA: 1) intra- or extracellular auto-oxidation of 6-OHDA that mostly leads to the generation of hydrogen peroxide and superoxide and hydroxyl radicals [15]; 2) Action of monoamine oxidase, which results in the formation of hydrogen peroxide [16], and 3) Direct inhibition in the respiratory chain 
complex I of mitochondrial [17]. Generation of reactive oxygen species (ROS) may be the result of these mechanisms, independently or together [18], [19]. For this reason, a vast range of studies is focused on oxidative stress and antioxidants.

Flavonoids are strong antioxidants due to the virtue of their phenolic structure as chelators and free radical scavengers [20]. The physiological effects of flavonoids are largely due to their antioxidant properties in plasma, which serve as an enzyme cleaner for ornithine carboxylase, protein kinase and calmodulin enzymes [19]. Epidemiological studies show that flavonoid intake will reduce the risk of coronary heart disease [21], stroke [22], diabetes [23], and cancer; including breast cancer [24], prostate cancer [25], lung cancer [26], colon cancer [27], and stomach cancer [28], [29].

Chalcones are considered as the precursors of flavonoids and isoflavonoids [30]. Due to the presence of unsaturated $\alpha-\beta$, (Enone) group between the two phenyl rings, chalcones possess many biological and pharmacological properties [31]. Therapeutic applications of these materials go back to the thousand-year history of using herbs and plants for medicinal purposes [32]. The most challenging aspect of the use of chalcones is its pharmacokinetic properties and metabolic instability. Though, it appears that changes in their structure can overcome this obstacle. Alterations of chalcones substitutes can produce different properties.

Numerous Studies have been done demonstrating the ability of Chalcones to act as anti-cancer [31] (prostate cancer [33], leukemia [34], gastric cancer [35], colon cancer [36], lung cancer [37], and breast and cervical cancer [38], [39]) agent. They have also shown to inhibit enzymatic activity [40], act as a tumor suppressor [41], nitric oxide blocker, modulator, and regulator [42].

In 2008, Nobre-Junior et al. investigated the neuroprotective effects of Chalcone, isolated from myracroduonu-randeuvao, on the toxicity of mesencephalic cells in rats with 6-OHDA. The results 
of this study showed the neuroprotective effects of chalcones, which can reduce the oxidative stress and apoptotic damage induced by 6-OHDA. These results also showed that Chalcones has the potential to be a therapeutic aid in the treatment of neurodegenerative disorders such as Parkinson's [43].

So far, many therapeutic approaches have been suggested for Parkinson's disease, including the administration of various drugs and surgeries. Since the administration of medicines only helps to improve the quality of life and increase the functional capacity of patients, the need to employ new compounds in people with PD is sensed.

Due to the chalcones various properties, such as anti-inflammatory, anti-leishmania, antimalarial, antivirus, anti-fungal, anti-metastatic, apoptotic, anti-parasitic, anti-angiogenic, antiappetite, anti-diabetic, antioxidant, etc. effects, this study aims to investigate the effects of new Chalcone derivatives, with different properties, on the PC12 cells, as an in vitro model of the Parkinson's disease. The results from this study is evaluated based on the previous experimental and theoretical report on the molecular structure, interactional behavior, and molecular resonance of these Chalcones, using Linear solvation energy relationship (LSER) model and time-dependent density functional theory and configuration interaction calculations [44].

\section{Results and Discussion}

It is well known that interactions of chemical materials depend on many parameters, such as chemical structure, active groups and solvent media. Solvent media plays a significant role especially in biological systems due to their complex nature. In such systems, polarizability/polarity, acidity and basicity are major players, simultaneously, which add to the complexity of an already complicated behavior in these media [45]-[47]. 
According to our previous experimental and theoretical study carried out on the molecular resonance and interactional behavior of these newly synthetic Chalcones via Linear solvation energy relationship (LSER) model and time-dependent density functional theory and configuration interaction calculations, the interactional behavior of these Chalcone compounds are governed by specific and non-specific interactions [31], [44]. Specific interactions include hydrogen bond donor ability (acidity) and hydrogen bond acceptor ability (basicity) whereas the non-specific interactions include polarity and polarizability interactions [48].

Results of the multiple linear analyses are presented, in detail, in Ref [44], (one can refer to Table.S.1 and Figure.S.1 in supplementary data).

Based on the calculations in Ref 44, interactional contribution equations of these Chalcones compounds are governed by the following equations:

$$
\begin{array}{ll}
v\left(\mathrm{~cm}^{-1}\right)=31242.81-131 \alpha-395 \beta-747 \pi^{*} & \mathrm{R}^{2}=0.84 \\
v\left(\mathrm{~cm}^{-1}\right)=31879+246 \alpha+447 \beta-711 \pi^{*} & \mathrm{R}^{2}=0.83 \\
v\left(\mathrm{~cm}^{-1}\right)=28799-290 \alpha-1168 \beta-273 \pi^{*} & \mathrm{R}^{2}=0.91
\end{array}
$$

The media parameters representing these interactions are as follows: acidity $-\alpha$; basicity $-\beta$; dipolarity/polarizability $-\pi^{*}\left(\mathrm{R}^{2}\right.$ : values of the regression coefficient). These parameters are usually are values between 0 and 1 , for example for DMSO, these parameters are $\alpha=0, \beta=0.76$ and $\pi^{*}=1$.

As seen from the presented equations, $\pi^{*}$ has the highest contribution in Chalcone 1 (Eq (1)) and Chalcone 2 (Eq (2)), and $\beta$ is the main player in Chalcone 3 (Eq (3)). 
In a healthy biological system the solvent parameters of the whole system is in balance. However, presence of a harmful foreign compound in a biological system, like 6-OHDA in the present study, disturbs this balance and alters the interactional environment, ensuing complications, such as ROS production, P53 expression and etc. In this regard, using chemical compounds, like Chalcones, as treatments in such biological systems is also affected and controlled by these parameters $(\alpha, \beta$, and $\left.\pi^{*}\right)$. As such, contributions of these parameters in the interaction of these Chalcone compounds defines the obtained behavioral results, which are presented in the following.

\subsection{Intracellular ROS levels with all three chalcones.}

Introduction of 6-OHDA to the PC12 cells results in the production of free radicals, which, as mentioned, were measured via ROS assay. This assay was done considering the effective time of 24 hours and low effective doses. All selected doses of Chalcone 1, Chalcone 2, and Chalcone 3 had significant effects with the positive control group. According to Figure 1, Chalcone 3 showed a greater ability to reduce the ROS production remarkably.

As said before, the 6-OHDA act to produce ROS through generation of hydrogen peroxide and superoxide and hydroxyl radicals, causing cell death. Treated with Chalcones 1, 2 and 3, the number of produced ROS is reduced. According to the interactional behaviour of the Chalcones, investigated before (ref 44), the dominant media parameter for Chalcones 1 and 2 is the nonspecific interactions - polarity/polarizability - and for the Chalcone 3 the main effective factor is the specific interactions - formation of complexes between hydrogen-bond donors (HBDs) and hydrogen-bond acceptors (HBAs).

Due to the high activity of Chalcones 1 and 2 in the presence of media with high polarity, a degree of interaction is observed between the 6-OHDA and Chalcones 1 and 2. These interactions 
not only reduce the effect of 6-OHDA and diminish its products, but also hinder the effect of 6OHDA on the cell due to the formation of complexes and blocks between the Chalcones and the 6-OHDA that decreases the effect of 6-OHDA on the production of ROS in the cells. As seen in Figure 1 ((a) and (b)), using Chalcones 1 and 2 in cell treatment results in diminishing the ROS. The higher the dosage of Chalcones in cells, the more interactions are occurred between the molecules and the less ROS is produced.

In the case of Chalcone 3, as mentioned before (see ref 44) the main factor in the inter/intra molecular interactions is the specific interactions - hydrogen bonding -, meaning that Chalcone 3 is significantly active in the presence of material with the capacity for specific interactions, like 6OHDA. This leads to a high degree of interactions between these two materials that concludes in preventing 6-OHDA from generating ROS. As can be seen from Figure 1 (c), there is a significant reduction in the production of ROS as a result of treatment with Chalcone 3 . This decrement is higher for Chalcone 3, in comparison to Chalcones 1 and 2 (Figure 1(d)).

\subsection{Western Blotting.}

Results of the expression of P53 protein in all three Chalcones showed a decrease in this protein for all concentrations, compared to the positive control group, and as shown in Figure 2, the reduction of the expression of this protein for Chalcone 3 is higher in comparison.

For Chalcone 1, there was no change in the expression of Bax and Bcl-2 protein, whereas for Chalcone 2 an increase is observed in the expression of Bcl-2 protein at the dose of $10 \mu \mathrm{m} / \mathrm{ml}$, and a reduction of the expression for the dose of $40 \mu \mathrm{m} / \mathrm{ml}$. Chalcone 3 showed an increment in the expression levels of these proteins by increasing the dose. 
It has been reported that 6-OHDA destroys catecholaminergic structures by the combined effect of reactive oxygen species (ROS) and quinones. It is assumed that the ROS initiate cellular oxidative stress and p-quinone mediates 6-OHDA-induced cell death. To cope with and manage various types of stress a large number of tightly regulated stress response pathways have evolved. The P53 pathway is the primary response to stress [49]. P53, activated by external and internal stress signals, promote its nuclear accumulation in an active form. In response to stress, P53 selectively regulates the expression of its target genes, which results in cell cycle arrest, apoptosis, or senescence [50].

This effect of 6-OHDA can be seen from Figure 2, for the positive control group. Treated with Chalcones 1, 2 and 3, different results are observed. According to ref 44, the non-specific (polarity/polarizability) and specific interactions (hydrogen bonding) play the major role in the interactions of these compounds.

For Chalcones 1, the expression of P53 is increased in all doses. Having the polarity/polarizabilty as the main factor in inter/intra molecular interactions of this material and a weaker ability for specific interactions, upon treatment with this material, there is little interactions between the 6OHDA and Chalcone 1. So, upon treatment with Chalcone 1, both 6-OHDA and Chalcone 1 act as a stress factor and result in the expression of P53 (Figure 2).

The interactional behavior of Chalcone 2 is similar to Chalcone 1 , however, beside the polarity/polarizability, the roll of hydrogen bond acceptor ability is stronger for Chalcone 2, in comparison to Chalcone 1. As a result, in treatment with this Chalcone, there is a major interaction between the 6-OHDA and the Chalcone 2 inside the cell. Thus, the effect of 6-OHDA and Chalcone 2 in triggering the P53 is reduced, and as seen from Figure 1 the expression of P53 is significantly diminished. 
For Chalcone 3, the main factor in the inter/intra-molecule interactions is the specific interactions. Treating the samples with Chalcone 3 results in a notable reduction in the expression of P53. Upon treatment with Chalcone 3, there is high interactions between Chalcone 3 and 6OHDA, since 6-OHDA possesses a high ability for specific interactions due to its molecular structure.

\subsection{Apoptosis Assessment.}

To further study the effect of Chalcones on the PC12 cells and the apoptosis of cells, an apoptosis assessment was carried out. The results of this evaluation via Annexin \& PI assay are shown in Figure 3, in which, low, medium and high doses of each Chalcone were assessed and compared. Doses of 10, 40 and $80 \mu \mathrm{g} / \mathrm{ml}$ of Chalcones 1 and 2 on the Parkinson model cells showed that the dose of $10 \mu \mathrm{g} / \mathrm{ml}$ reduces the apoptosis, whereas increasing the dose to 40 and $80 \mu \mathrm{g} / \mathrm{ml}$ shows an increment in the apoptosis rate. However, Chalcone 3 presented no increase in apoptosis at doses 10,40 and $80 \mu \mathrm{g} / \mathrm{ml}$ (Figure 3).

\subsection{Viability assay.}

Evaluation of the viability of the Parkinson's cells treated with $5-10-20-40 \mu \mathrm{g} / \mathrm{ml}$ doses of Chalcones 1, 2 and 3 showed that: In 24 hours Chalcone 1, had a significant increase in the number of the live cells compared to the positive control group. However, $80-160 \mu \mathrm{g} / \mathrm{ml}$ doses presented a considerable decrease over 24 hours in comparison to the positive control. At higher doses, as seen from the results of Annexin \& PI (Figure 3), Chalcone 1 appears to have cytotoxicity and causes cell death. In 48 hours, the concentrations less than $40 \mu \mathrm{g} / \mathrm{ml}$ showed a notable increase in the 
viability of the cells, and doses of 40, 80 and $160 \mu \mathrm{g} / \mathrm{ml}$ reduced the number of live cells (Figure 4).

As shown before, upon treatment with Chalcone 1, ROS assay showed a decrement in the generation of ROS (Figure 1(a)) and Western Blotting confirmed an increase in the expression level of P53 (Figure 2(c)). Consequently, the sum of paths to cell death comes down to an increment in the number of live cells for low doses. However, according to apoptosis assessment (Figure 3), raising the dose results in a higher cell death, meaning using higher doses lead to Chalcone 1 acting as a strong P53 trigger, as seen from Figure 4, and reducing cell viability.

The effective doses of Chalcone 2 in increasing the cell viability after $24 \mathrm{~h}$ were 5, 10, 20, 40 $\mu \mathrm{g} / \mathrm{ml}$, which showed a significant increase in the number of viable cells compared to the positive control group $(\mathrm{P}<0.01)$. An increase in dose resulted in a reduction of the number of live cells, in comparison to the positive control group and other doses.

According to the previous results of ROS and P53 in treatment with Chalcone 2, there were reduction for both ROS and P53 (Figures 2(b) and 3(c), respectively) in PC12 cells. Evidently, using Chalcone 2 for treatment of cells leads to a decrement in cell death (Figure 5). For Chalcone 2, similar to Chalcone 1, cell viability is increased for low doses, but for higher doses the number of live cells are reduced; a result also confirmed by the Annexin \& PI assay (Figure (4)).

The percentage of the viability of PC12 cells of Parkinson's model treated with Chalcone 3 after 24 and 48 hours showed that all doses significantly increased the viability of cells ( $\mathrm{P}<0.01)$. According to Figure 6, it can be seen that Chalcone 3 can reduce 6-OHDA-induced cytotoxicity in PC12 cells, and it does not show toxicity at higher doses. This result is also validated via the Annexin \& PI assay (Figure 3). 
So, the most significant result obtained was from Chalcone 3. The data from Figures 2(c) and 3(c) presented that Chalcone 3 showed the highest reduction in the generation of ROS and expression of P53. As can be seen from Figure 6, Chalcone 3 shows remarkable increase in cell viability of the PC12 cells. Plus, according to the Annexin \& PI assay (Figure 3), Chalcone 3 presents no cytotoxicity even for higher doses and longer duration of time.

All in all, PC12 cell line treated with all three Chalcone derivatives, at low doses, after $48 \mathrm{~h}$, revealed significant increase in cell viability compared to the positive control group (Figure 7). As can be seen, results of treatment with Chalcone 3 is different from the other two Chalcones, in the sense that increasing its dose does not lead to an increment in toxicity for longer duration of time. This high activity of Chalcone 3 makes this material a superb candidate as a new treatment drug for Parkinson's disease.

\section{Materials and methods}

Materials. The PC12 cell line was purchased from the Pasteur Institute of Iran. 6-Hydroxy dopamine (Sigma), Fetal bovine serum (FBS) (Gibco), dimethyl sulfoxide (Sigma) and 2-7dichlorofluorescent diacetate (DCF_DA) and Annexin \& PI kit were procured from SigmaAldrich, and Bax, P53, Bcl-2 antibodies were purchased from Abcam.

Chalcones 1, 2 and 3 were synthesized with the chemical structure as shown in Figure 8. The details of synthesis are reported elsewhere [51]. 


\subsection{Cell culture.}

Cells were cultured in flasks containing RPMI and 10\% FBS medium, Penicillin/Streptomycin antibiotics, and placed in $\mathrm{CO} 2$ incubator with $95 \%$ humidity, at $37^{\circ} \mathrm{C}$. After forming a layer on the bottom of the flask, cells were passaged thrice using Trypsin and used for experiments.

\subsection{Experimental groups.}

Negative control group: The group that did not receive any treatment.

Sham group: received DMSO, the solvent of 6-HODA, as well as Chalcones' solvent.

Positive control group: received a dose of $75 \mu \mathrm{M}, 6$-HODA.

And Test groups: groups that received 6-HODA along with different doses of Chalcones 1, 2, and $3(5-10-20-40-80-160 \mu \mathrm{g} / \mathrm{ml})$.

\subsection{MTT assay.}

MTT assay was performed to determine the effects of three new Chalcone derivatives on 6OHDA treated PC12 cells. Cells were cultured in a 96-well plate. One day after the cells adhered to the bottom of the plate, 6-OHDA with a concentration of $75 \mu \mathrm{M}$ was added to the cells and then treated with different doses of Chalcones, at $24 \mathrm{~h}$ and $48 \mathrm{~h}$. Afterward, the final volume of the columns, with said treatments, was brought up to $100 \mu \mathrm{L}$. After the incubation was complete, $100 \mu \mathrm{L}$ of MTT was added to the wells and incubated for $2 \mathrm{~h}$ to $4 \mathrm{~h}$. Following, $100 \mu \mathrm{L}$ of DMSO was added to the wells and the plate was placed in an Elisa reader, with the wavelength of 570nm. The optical absorption rate was calculated using the following formula. 


$$
\text { Percentage of live cells }=\frac{(\text { optical absorption of the test group })}{(\text { optical absorption of the control group })} \times 100
$$

\subsection{ROS assay.}

ROS assay was used to measure and survey the production of free radicals. The effect of Chalcones on the ROS level was evaluated using DCF-DA. PC12 cells were cultured in a 24-well plate for 24h. Cells treated with 6-OHDA were treated with different concentrations of Chalcones. After incubation, cells were washed with PBS, and after removing the PBS, $1 \mathrm{ml}$ dichlorofluorescent diacetate (DCF) with a concentration of $10 \mu \mathrm{M}$ was added to the wells, in the dark, and incubated for 30 minutes. With the incubation time ending, DCF was removed from the wells and the cells were washed with PBS. For evaluation of the wells, $1 \mathrm{ml}$ of PBS was used and an Elisa Reader with a wavelength of $485 / 528 \mathrm{~nm}$ recorded the absorption of the cells.

\subsection{Annexin \& PI assay.}

Annexin-V/propidium iodide method (A-V/PI) is a common flow cytometric method for the multiparametric analysis of cells in apoptosis. Annexin \& PI assay was done according to the method mentioned in the Roche catalog. Cells were cultured and treated, and after 24 hours, they were treated with Chalcone, and evaluated under an inverted microscope, then collected in separate micro-tubes on ice. Afterward, the cells were centrifuged at 2,000 rpm for 5 minutes, and the cell plaque was collected. The Annexin V and PI were added in order and in a specific time, and the apoptotic cells were detected and counted in a flow cytometer. 


\subsection{Western blotting P53, Bax, Bcl2.}

The SDS PAGE gel was used to purify proteins of U87MG cells. The protein was extracted from the cell, and was placed on the SDS-PAGE gel. After the sample thawed, the electroplating step was performed and the gel-protein samples were transferred to the PVDF membrane, and eventually the protein samples, which were revealed on the PVDF membrane, were detected using the ECL kit. The Bcl-2 antibodies were added to the membrane. Within 24 hours, a secondary antibody was added so that the entire surface of the membrane was covered. The membrane container and secondary antibodies were placed on a slow-moving pad at ambient temperature for an hour. After the incubation time, the secondary antibodies were removed, and then washed by Tris-buffered saline (TBS) for 3 to 10 minutes.

Statistical test. To compare the mean value of data between the groups, the results were analyzed using the SPSS software via one way ANOVA, for all groups, using Tukey's test with three repeats for each test (significance level is considered to be $\mathrm{P}<0.05$ ).

\section{Conclusion}

Chalcones; derivatives of (trans-1 and 3-diaryl-2-propene-1-one), widely found in edible plants, possess biological activities, such as; antioxidant, cytotoxicity, anticancer, antibacterial, antihistamine, and anti-inflammatory properties. With an increase in pharmaceutical applications, Chalcones and its derivatives have attracted much attention. New Chalcone compounds exhibit better and stronger biological effects, so this study aimed to investigate the effect of three new Chalcone derivatives on the cell death and oxidative stress in PC12 Parkinson model cells. 
To do so, MTT assay, ROS, apoptosis, Bax, Bcl2, and P53 proteins using Western blotting were carried out. Results were analyzed via one-way ANOVA and the Duncan test less than 0.05 was considered significant $(\mathrm{P}<0.05)$.

The results showed that the doses of 5-10-20-40 $\mu \mathrm{g} / \mathrm{ml}$ of Chalcone 1 and 2 , after $24 \mathrm{~h}$, showed a significant increase in cell viability, compared to the positive control group (the group that received $75 \mu \mathrm{M}$ 6-OHDA), but doses of 80 and $160 \mu \mathrm{g} / \mathrm{ml}$ were toxic and presented a noticeable decrease in viability. There was also a significant difference in vitality gained at two-time points of 24 and 48 hours. Plus, this study showed that Chalcone 3, which according to Figure 8 has a high structural difference with the other two Chalcone compounds, had more protective properties against 6-OHDA-induce cell death in PC12 cells, and for all doses it increased the number of cells with normal morphology. Furthermore, Chalcone 3 did not show toxicity with increasing the dosage, and can be said to be harmless to cells. Additionally, the results of apoptosis assay with Annexin \& PI and Bax/bcl2 ratio also showed that Chalcones 1 and 2 can have toxic effects at high doses, and possess the dose-dependent cytotoxic activity and apoptotic activity. However, Chalcone 3 only increased the anti-apoptotic effect. So, each different compound of Chalcone can be used specifically for its protection or anti-cancer properties.

To sum up, the results in the present study showed that Chalcone 3 had a more neuroprotective effect with stronger antioxidant properties against 6-OHDA cell death, in com-parison to Chalcones 1 and 2. Chalcones with antioxidant properties can act as a defense mechanism against oxidative stress and inflammatory responses. Chalcone derivatives can play an important role in regulating the intracellular and extracellular ROS. They are also an important factor in eliminating the reactive oxygen and removing the oxidative damage from the body and cellular damage. 


\title{
AUTHOR INFORMATION
}

Corresponding Authors:

次 Sh. Golghasemi Sorkhabi, Email: Shahla.Golghasemi@gmail.com

* R. Kian, Email: roshanak_kian@tabrizu.ac.ir

\section{Author Contributions}

M.Farhadi conceived and designed the experiments, and collected the data. Z. Sanadgol performed the experiments and collected data. SB. Jameie collected the data and wrote the manuscript. A.N. Shamkhali analyzed the data. E. Kashani synthesized and optimized the compounds. N. N. Pesyan synthesized and optimized the compounds. R. Kian studied, analyzed and evaluated the data, and wrote the manuscript. Sh. Golghasemi Sorkhabi studied, analyzed and evaluated the data, wrote and edited the manuscript. M.S. Zakerhamidi analyzed and evaluated the data, and wrote and edited the manuscript.

\section{Author Contributions}

These authors contributed equally to this work.

\author{
ABBREVIATIONS \\ PD, Parkinson's disease; 6-OHDA, 6-hydroxydopamine; ROS, Reactive oxygen species; \\ DCF_DA, 2-7-dichlorofluorescent diacetate; FBS, Fetal bovine serum; A-V/PI, Annexin- \\ V/propidium iodide method; HBD, Hydrogen-bond donor; HBA, Hydrogen-bond acceptor;.
}




\section{References:}

[1] E. Hirsch, A. M. Graybiel, and Y. A. Agid, "Melanized dopaminergic neurons are differentially susceptible to degeneration in Parkinson's disease," Nature, vol. 334, no. 6180, pp. 345-348, Jul. 1988, doi: 10.1038/334345a0.

[2] J. A. Morales-García et al., "Glycogen Synthase Kinase-3 Inhibitors as Potent Therapeutic Agents for the Treatment of Parkinson Disease.," ACS Chem. Neurosci., vol. 4, no. 2, pp. 350-360, Feb. 2013, doi: 10.1021/cn300182g.

[3] A. J. Hughes, S. E. Daniel, S. Blankson, and A. J. Lees, "A clinicopathologic study of 100 cases of Parkinson's disease.," Arch. Neurol., vol. 50, no. 2, pp. 140-148, Feb. 1993, doi: 10.1001/archneur.1993.00540020018011.

[4] W. Poewe et al., "Parkinson disease," Nat. Rev. Dis. Prim., vol. 3, no. 1, p. 17013, 2017, doi: $10.1038 /$ nrdp.2017.13.

[5] J. A. Obeso et al., "Missing pieces in the Parkinson's disease puzzle," Nat. Med., vol. 16, p. $653,2010$.

[6] F. D. Dick et al., "Environmental risk factors for Parkinson's disease and parkinsonism: The Geoparkinson study," Occup. Environ. Med., vol. 64, p. 666, 2007.

[7] D. Twelves, K. S. Perkins, and C. Counsell, "Systematic review of incidence studies of Parkinson's disease," Mov. Disord., vol. 18, p. 19, 2003.

[8] M. W. C. Rousseaux et al., "Progressive dopaminergic cell loss with unilateral-to-bilateral progression in a genetic model of Parkinson disease.," Proc. Natl. Acad. Sci. U. S. A., vol. 109, no. 39, pp. 15918-15923, Sep. 2012, doi: 10.1073/pnas.1205102109.

[9] D. Kirik, L. E. Annett, C. Burger, N. Muzyczka, R. J. Mandel, and A. Björklund, "Nigrostriatal $\alpha$-synucleinopathy induced by viral vector-mediated overexpression of 
human $\alpha$-synuclein: A new primate model of Parkinson\&\#039;s disease," Proc. Natl. Acad. Sci., vol. 100, no. 5, pp. 2884 LP - 2889, Mar. 2003, doi: 10.1073/pnas.0536383100.

[10] E. Leem et al., "Naringin protects the nigrostriatal dopaminergic projection through induction of GDNF in a neurotoxin model of Parkinson's disease," J. Nutr. Biochem., vol. 25, no. 7, pp. 801-806, 2014, doi: https://doi.org/10.1016/j.jnutbio.2014.03.006.

[11] X. Zhang, L. Lu, S. Liu, W. Ye, J. Wu, and X. Zhang, "Acetylcholinesterase deficiency decreases apoptosis in dopaminergic neurons in the neurotoxin model of Parkinson's disease," Int. J. Biochem. Cell Biol., vol. 45, no. 2, pp. 265-272, 2013, doi: https://doi.org/10.1016/j.biocel.2012.11.015.

[12] J.-F. Chen et al., "Neuroprotection by Caffeine and A2A Adenosine Receptor Inactivation in a Model of Parkinson's Disease," J. Neurosci., vol. 21, no. 10, p. RC143 LP-RC143, May 2001, doi: 10.1523/JNEUROSCI.21-10-j0001.2001.

[13] N. Simola, M. Morelli, and A. R. Carta, "The 6-Hydroxydopamine model of parkinson's disease," Neurotox. Res., vol. 11, no. 3, pp. 151-167, 2007, doi: 10.1007/BF03033565.

[14] J. Rodriguez-Pallares, J. A. Parga, A. Muñoz, P. Rey, M. J. Guerra, and J. L. LabandeiraGarcia, "Mechanism of 6-hydroxydopamine neurotoxicity: the role of NADPH oxidase and microglial activation in 6-hydroxydopamine-induced degeneration of dopaminergic neurons," J. Neurochem., vol. 103, no. 1, pp. 145-156, Oct. 2007, doi: https://doi.org/10.1111/j.1471-4159.2007.04699.x.

[15] D. Blum et al., "Molecular pathways involved in the neurotoxicity of 6-OHDA, dopamine and MPTP: contribution to the apoptotic theory in Parkinson's disease.," Prog. Neurobiol., vol. 65, no. 2, pp. 135-172, Oct. 2001, doi: 10.1016/s0301-0082(01)00003-x.

[16] K. Chiba, A. Trevor, and N. Castagnoli, "Metabolism of the neurotoxic tertiary amine, 
MPTP, by brain monoamine oxidase," Biochem. Biophys. Res. Commun., vol. 120, no. 2, pp. 574-578, 1984, doi: https://doi.org/10.1016/0006-291X(84)91293-2.

[17] Y. Glinka, K. F. Tipton, and M. B. H. Youdim, "Nature of Inhibition of Mitochondrial Respiratory Complex I by 6-Hydroxydopamine," J. Neurochem., vol. 66, no. 5, pp. 20042010, May 1996, doi: https://doi.org/10.1046/j.1471-4159.1996.66052004.x.

[18] J. F. Harrison, S. B. Hollensworth, D. R. Spitz, W. C. Copeland, G. L. Wilson, and S. P. LeDoux, "Oxidative stress-induced apoptosis in neurons correlates with mitochondrial DNA base excision repair pathway imbalance," Nucleic Acids Res., vol. 33, no. 14, pp. 4660-4671, Aug. 2005, doi: 10.1093/nar/gki759.

[19] M. L. Circu and T. Y. Aw, "Reactive oxygen species, cellular redox systems, and apoptosis," Free Radic. Biol. Med., vol. 48, no. 6, pp. 749-762, 2010, doi: https://doi.org/10.1016/j.freeradbiomed.2009.12.022.

[20] I. Al Ghouleh et al., "Oxidases and peroxidases in cardiovascular and lung disease: New concepts in reactive oxygen species signaling," Free Radic. Biol. Med., vol. 51, no. 7, pp. 1271-1288, 2011, doi: https://doi.org/10.1016/j.freeradbiomed.2011.06.011.

[21] V. Ponzo et al., "Dietary flavonoid intake and cardiovascular risk: a population-based cohort study," J. Transl. Med., vol. 13, no. 1, p. 218, 2015, doi: 10.1186/s12967-015-05732.

[22] J. Mursu, S. Voutilainen, T. Nurmi, T.-P. Tuomainen, S. Kurl, and J. T. Salonen, "Flavonoid intake and the risk of ischaemic stroke and CVD mortality in middle-aged Finnish men: the Kuopio Ischaemic Heart Disease Risk Factor Study.," Br. J. Nutr., vol. 100, no. 4, pp. 890-895, Oct. 2008, doi: 10.1017/S0007114508945694.

[23] N. M. Wedick et al., "Dietary flavonoid intakes and risk of type 2 diabetes in US men and 
women.," Am. J. Clin. Nutr., vol. 95, no. 4, pp. 925-933, Apr. 2012, doi: 10.3945/ajcn.111.028894.

[24] J. Peterson et al., "Flavonoid intake and breast cancer risk: a case-control study in Greece," Br. J. Cancer, vol. 89, no. 7, pp. 1255-1259, 2003, doi: 10.1038/sj.bjc.6601271.

[25] K. Guo, Z. Liang, L. Liu, F. Li, and H. Wang, "Flavonoids intake and risk of prostate cancer: a meta-analysis of observational studies," Andrologia, vol. 48, no. 10, pp. 1175-1182, Dec. 2016, doi: https://doi.org/10.1111/and.12556.

[26] Y. Cui et al., "Dietary flavonoid intake and lung cancer--a population-based case-control study," Cancer, vol. 112, no. 10, pp. 2241-2248, May 2008, doi: 10.1002/cncr.23398.

[27] Y. Li, T. Zhang, and G. Y. Chen, "Flavonoids and Colorectal Cancer Prevention," Antioxidants (Basel, Switzerland), vol. 7, no. 12, p. 187, Dec. 2018, doi: 10.3390/antiox 7120187 .

[28] H. D. Woo and J. Kim, "Dietary flavonoid intake and risk of stomach and colorectal cancer," World J. Gastroenterol., vol. 19, no. 7, pp. 1011-1019, Feb. 2013, doi: 10.3748/wjg.v19.i7.1011.

[29] N. P. Bondonno et al., "Flavonoid intake is associated with lower mortality in the Danish Diet Cancer and Health Cohort," Nat. Commun., vol. 10, no. 1, p. 3651, 2019, doi: 10.1038/s41467-019-11622-x.

[30] A. N. Panche, A. D. Diwan, and S. R. Chandra, "Flavonoids: an overview," J. Nutr. Sci., vol. 5, pp. e47-e47, Dec. 2016, doi: 10.1017/jns.2016.41.

[31] R. Kian, M. S. Zakerhamidi, A. N. Shamkhali, and E. Kashani, "Study of the variation of intra/intermolecular interactions and configuration of a group of Enone anticancer drugs as a result of solvation," J. Mol. Liq., vol. 274, pp. 1-14, 2019, doi: 
10.1016/j.molliq.2018.10.081.

[32] L. Mirossay, L. Varinská, and J. Mojžišs, “Antiangiogenic Effect of Flavonoids and Chalcones: An Update," Int. J. Mol. Sci., vol. 19, no. 1, p. 27, Dec. 2017, doi: 10.3390/ijms19010027.

[33] E. Szliszka, Z. P. Czuba, B. Mazur, L. Sedek, A. Paradysz, and W. Krol, "Chalcones enhance TRAIL-induced apoptosis in prostate cancer cells," Int. J. Mol. Sci., vol. 11, no. 1, pp. 1-13, Dec. 2009, doi: 10.3390/ijms11010001.

[34] M. F. Maioral et al., "Apoptotic events induced by synthetic naphthylchalcones in human acute leukemia cell lines," Biochimie, vol. 95, no. 4, pp. 866-874, 2013, doi: https://doi.org/10.1016/j.biochi.2012.12.001.

[35] S. Zhang et al., "A novel chalcone derivative S17 induces apoptosis through ROS dependent DR5 up-regulation in gastric cancer cells," Sci. Rep., vol. 7, no. 1, p. 9873, 2017, doi: 10.1038/s41598-017-10400-3.

[36] D. Predes et al., "The Chalcone Lonchocarpin Inhibits Wnt/ $\beta$-Catenin Signaling and Suppresses Colorectal Cancer Proliferation," Cancers (Basel)., vol. 11, no. 12, p. 1968, Dec. 2019, doi: 10.3390/cancers11121968.

[37] G. Chen et al., "A natural chalcone induces apoptosis in lung cancer cells: 3D-QSAR, docking and an in vivo/vitro assay," Sci. Rep., vol. 7, no. 1, p. 10729, 2017, doi: 10.1038/s41598-017-11369-9.

[38] M. A. Tantawy, F. M. Sroor*, M. F. Mohamed*, M. E. El-Naggar, F. M. Saleh, and H. M. H. and I. A. Abdelhamid*, "Molecular Docking Study, Cytotoxicity, Cell Cycle Arrest and Apoptotic Induction of Novel Chalcones Incorporating Thiadiazolyl Isoquinoline in Cervical Cancer," Anti-Cancer Agents in Medicinal Chemistry, vol. 20, no. 1. pp. 70-83, 
2020, doi: http://dx.doi.org/10.2174/1871520619666191024121116.

[39] B. Ren, M. Ablise, X. Yang, B. Liao, and Z. Yang, "Synthesis and biological evaluation of $\alpha$-methyl-chalcone for anti-cervical cancer activity,” Med. Chem. Res., vol. 26, no. 9, pp. 1871-1883, 2017, doi: 10.1007/s00044-017-1891-0.

[40] B. Zhou and C. Xing, "Diverse Molecular Targets for Chalcones with Varied Bioactivities," Med. Chem. (Los. Angeles)., vol. 5, no. 8, pp. 388-404, Aug. 2015, doi: 10.4172/21610444.1000291.

[41] G. Silva et al., "Trans-chalcone increases p53 activity via DNAJB1/HSP40 induction and CRM1 inhibition," PLoS One, vol. 13, no. 8, pp. e0202263-e0202263, Aug. 2018, doi: 10.1371/journal.pone.0202263.

[42] D. H. Kim, H. Li, Y. E. Han, J. H. Jeong, H. J. Lee, and J.-H. Ryu, "Modulation of Inducible Nitric Oxide Synthase Expression in LPS-Stimulated BV-2 Microglia by Prenylated Chalcones from Cullen corylifolium (L.) Medik. through Inhibition of I-kB $\alpha$ Degradation,” Molecules, vol. 23, no. 1, p. 109, Jan. 2018, doi: 10.3390/molecules23010109.

[43] H. V Nobre-Junior et al., "Neuroprotective Actions of Tannins from Myracrodruon urundeuva on 6-Hydroxydopamine-Induced Neuronal Cell Death," J. Herbs. Spices Med. Plants, vol. 13, no. 2, pp. 41-57, Jan. 2008, doi: 10.1300/J044v13n02_04.

[44] R. Kian, M. S. Zakerhamidi, A. N. Shamkhali, E. Kashani, and N. Noroozi Pesyan, "Investigation of interactional behavior and relative photo-physical properties in a group of bioactive compounds," J. Photochem. Photobiol. A Chem., vol. 381, no. October 2018, p. 111873, Aug. 2019, doi: 10.1016/j.jphotochem.2019.111873.

[45] M. C. Almandoz, M. I. Sancho, P. R. Duchowicz, and S. E. Blanco, "UV-Vis spectroscopic study and DFT calculation on the solvent effect of trimethoprim in neat solvents and 
aqueous mixtures," Spectrochim. Acta - Part A Mol. Biomol. Spectrosc., vol. 129, pp. 5260, 2014, doi: 10.1016/j.saa.2014.02.191.

[46] G. V. Muddapur, R. M. Melavanki, P. G. Patil, D. Nagaraja, and N. R. Patil, "Photophysical properties of 3MPBA: Evaluation and co-relation between solvatochromism and quantum yield in different solvents," J. Mol. Liq., vol. 224, pp. 201-210, 2016, doi: 10.1016/j.molliq.2016.09.102.

[47] M. S. Zakerhamidi, K. Nejati, S. Golghasemi Sorkhabi, and M. Saati, "Substituent and solvent effects on the spectroscopic properties and dipole moments of hydroxyl benzaldehyde azo dye and related Schiff bases," J. Mol. Liq., vol. 180, pp. 225-234, 2013.

[48] M. S. Zakerhamidi and S. G. Sorkhabi, "Solvent effects on the molecular resonance structures and photo-physical properties of a group of oxazine dyes," J. Lumin., vol. 157, pp. 220-228, 2015, doi: 10.1016/j.jlumin.2014.08.062.

[49] L.-W. Hu, J.-H. Yen, Y.-T. Shen, K.-Y. Wu, and M.-J. Wu, "Luteolin modulates 6hydroxydopamine-induced transcriptional changes of stress response pathways in PC12 cells," PLoS One, vol. 9, no. 5, pp. e97880-e97880, May 2014, doi: 10.1371/journal.pone.0097880.

[50] S. Haupt, M. Berger, Z. Goldberg, and Y. Haupt, “Apoptosis - the p53 network," J. Cell Sci., vol. 15, no. 116, pp. 4077-85, 2003, doi: 10.1242/jcs.00739.

[51] N. N. Pesyan, S. Noori, S. Poorhassan, and E. Şahin, "New spiro (thio) barbiturates based on cyclohexanone and bicyclo [3.1.1]heptan-6-one by nonconcerted [1+5] cycloaddition reaction and their conformational structures," Bull. Chem. Soc. Ethiop., vol. 28, no. 3, p. 423, Sep. 2014, doi: 10.4314/bcse.v28i3.12. 


\section{Figure Captions:}

Figure 1: Intracellular ROS production of (a) Chalcone 1, (b) Chalcone 2, and (c) Chalcone 3. (d) Comparison of ROS production for Chalcones 1, 2, and 3 in low concentrations $(5,10$ and 20 $\mu \mathrm{g} / \mathrm{ml}) .{ }^{*}$ Significant difference with the positive control group at the same time $(\mathrm{P}<0.01)$.

Figure 2: (a) Western Blotting analysis for (b) Bax/Bcl-2 proteins and (c) expression of P53, for Chalcones 1,2, and 3 with concentrations of $10,40,80 \mu \mathrm{g} / \mathrm{ml}$. $\beta$-actin was used as control for loading.

Figure 3. Results of Annexin \& PI for (a) Chalcone 1, (b) Chalcone 2, (c) Chalcone 3

Figure 4. Viability percentage of PC12 cells treated with different concentrations of Chalcone 1 after (a) 24 and (b) 48 hour. \# Significant difference with the negative control group at the same time ( $\mathrm{p}<0.01) . *$ Significant difference with the positive control group at the same time $(\mathrm{p}<0.01)$ Figure 5. Viability percentage of PC12 cells treated with different concentrations of Chalcone 2 after (a) 24 and (b) 48 hour. \# Significant difference with the negative control group at the same time ( $\mathrm{p}<0.01) . *$ Significant difference with positive control group at the same time $(\mathrm{p}<0.01)$

Figure 6. Viability percentage of PC12 cells treated with different concentrations of Chalcone 3 after (a) 24 and (b) 48 hours. \# Significant difference with the negative control group at the same time ( $\mathrm{p}<0.01)$ * Significant difference with the positive control group at the same time. $(\mathrm{P}<0.01)$ Figure 7. Comparison of the viability of Chalcones 1, 2, and 3 for 48 hours \# significant difference with the negative control group at the same time $(\mathrm{p}<0.01)$. Significant difference with the positive control group at the same time $(\mathrm{p}<0.01)$

Figure 8. Chemical structures of (a) 6- OHDA, (b) Chalcone 1, (c) Chalcone 2, (d) Chalcone 3. 
Figures
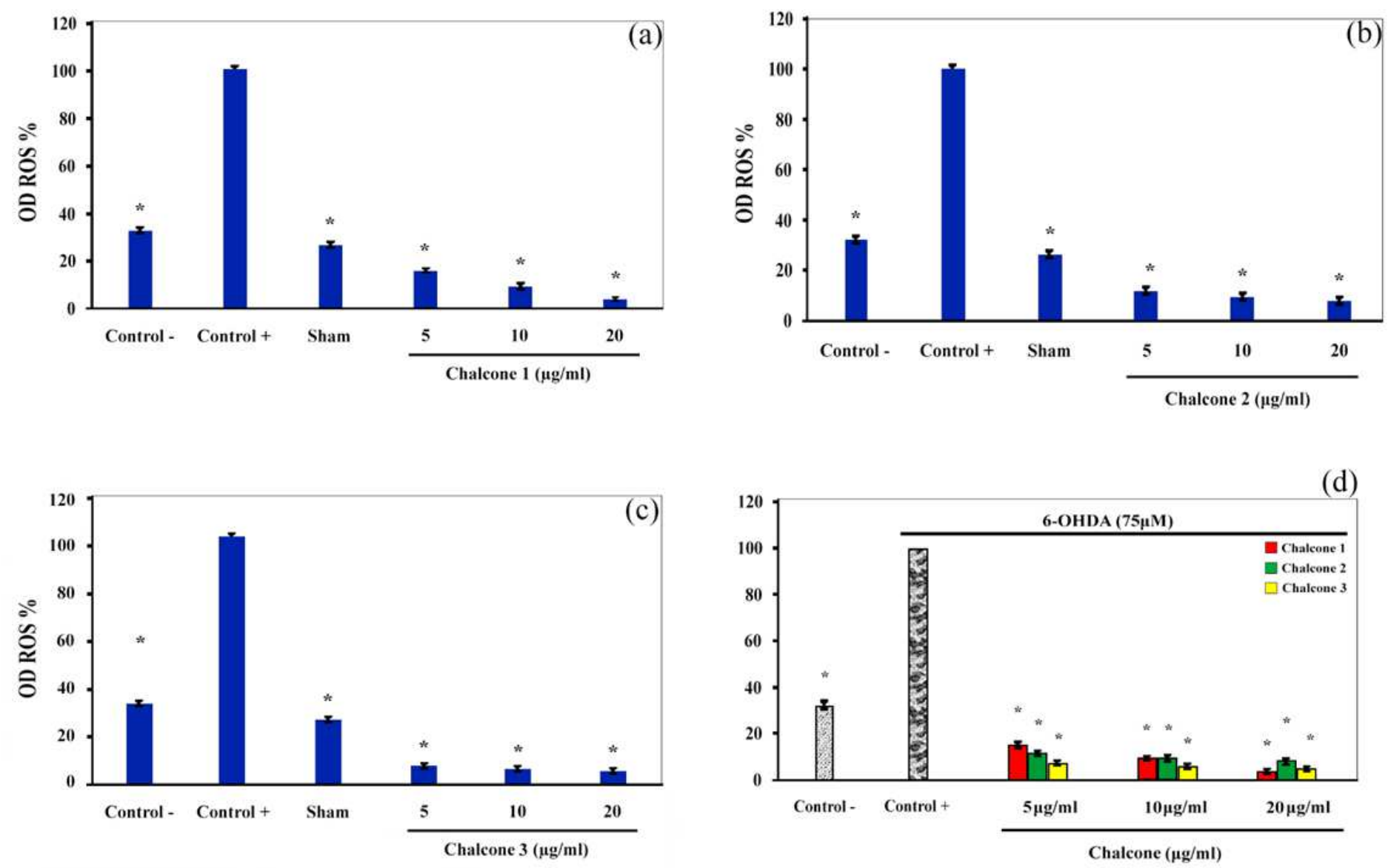

Figure 1

Intracellular ROS production of (a) Chalcone 1, (b) Chalcone 2, and (c) Chalcone 3. (d) Comparison of ROS production for Chalcones 1, 2, and 3 in low concentrations $(5,10$ and $20 \mu \mathrm{g} / \mathrm{ml})$. * Significant difference with the positive control group at the same time $(P<0.01)$. 
P53

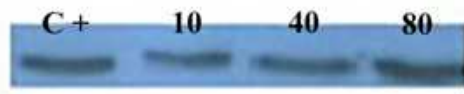

Bax

Bcl2

$\beta$-actin

P53

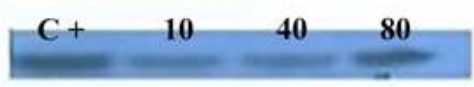

Bax

Bel2

$\beta$-actin

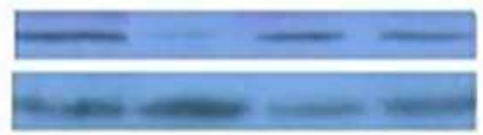

Chalcone 2

\section{Chalcone 1}

Chalcone 2

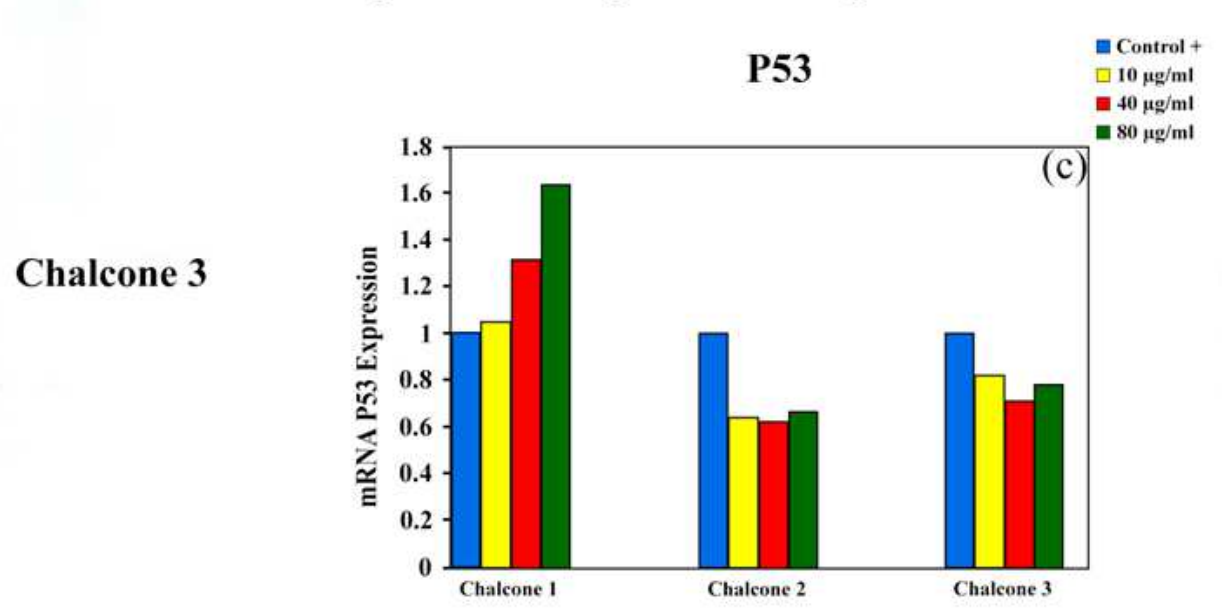

Figure 2

(a) Western Blotting analysis for (b) Bax/Bcl-2 proteins and (c) expression of P53, for Chalcones 1,2, and 3 with concentrations of $10,40,80 \mu \mathrm{g} / \mathrm{ml}$. $\beta$-actin was used as control for loading. 

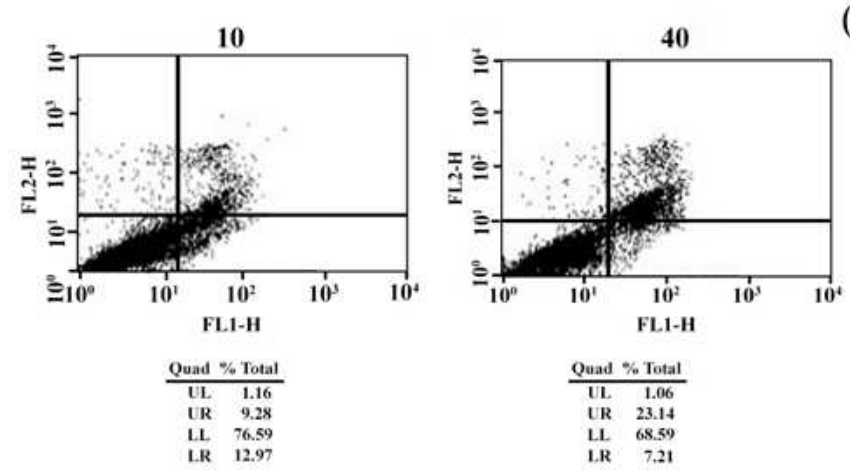

(a)
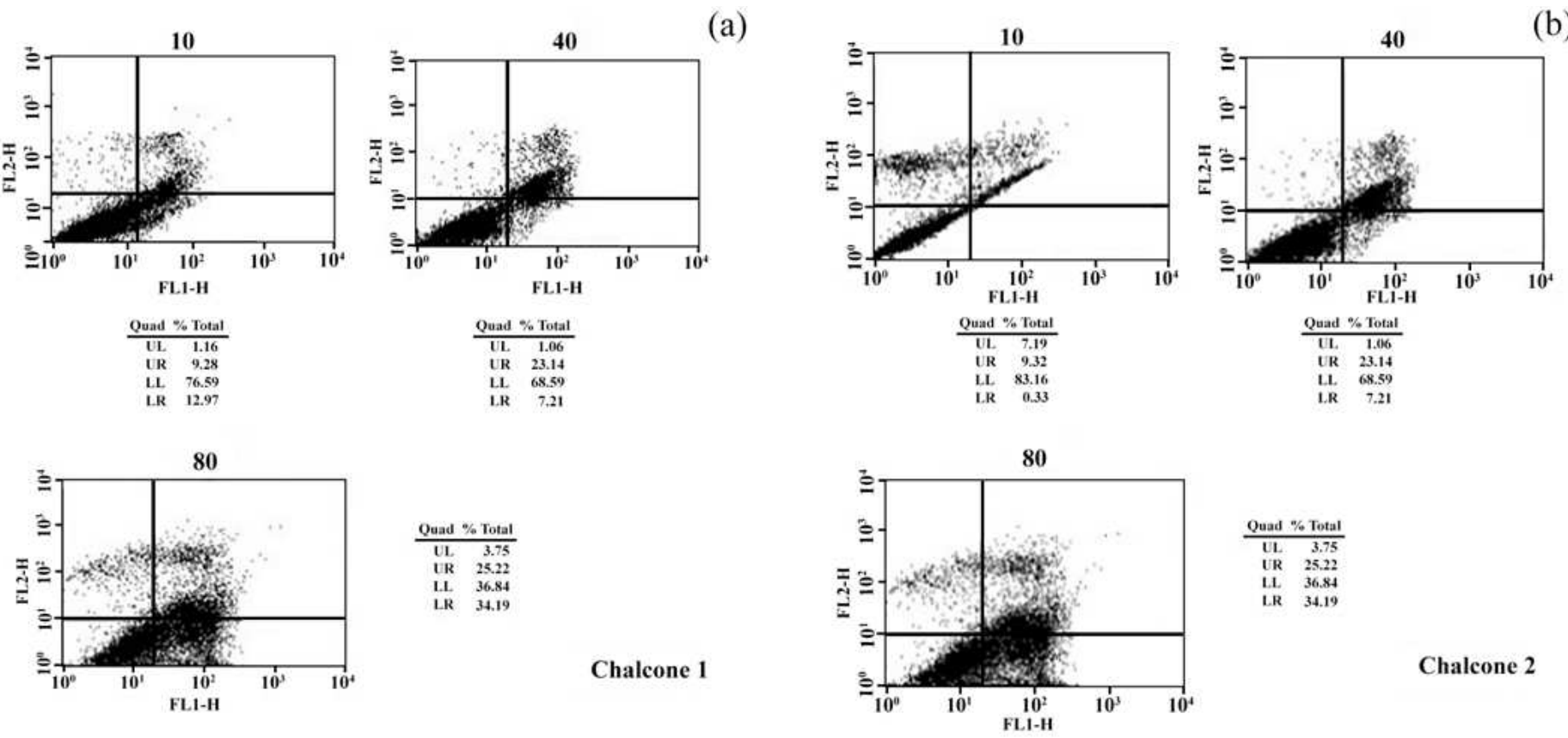

Chalcone 1

Chalcone 2
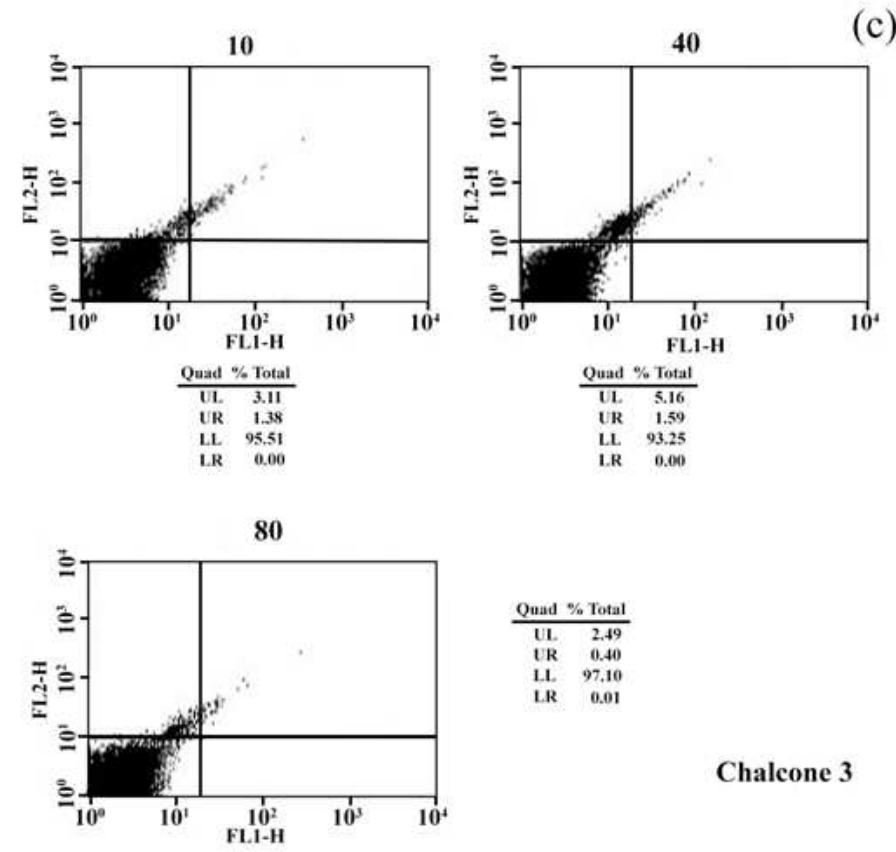

Chalcone 3

Figure 3

Results of Annexin \& PI for (a) Chalcone 1, (b) Chalcone 2, (c) Chalcone 3 
(a)

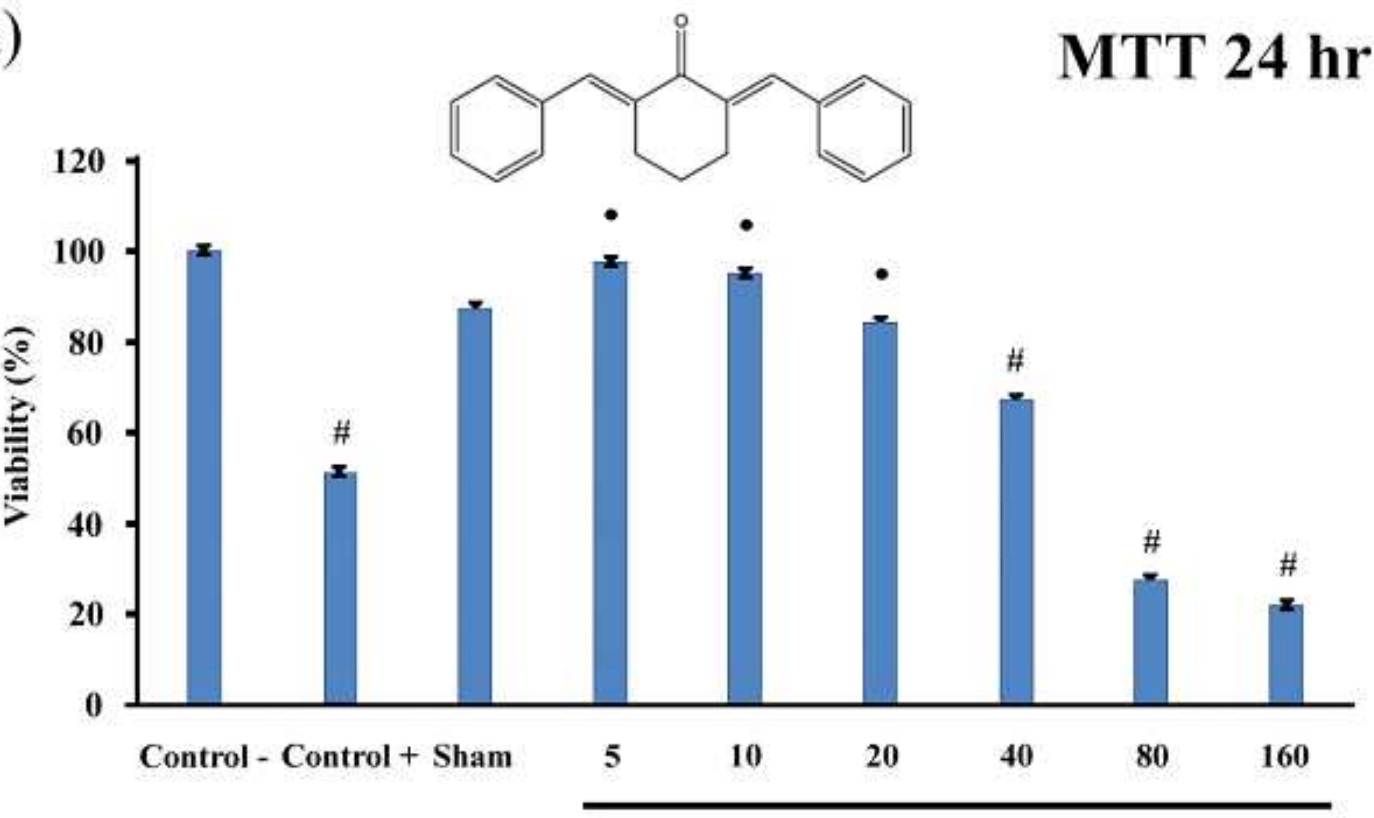

Chalcone $1(\mu \mathrm{g} / \mathrm{ml})$

(b)

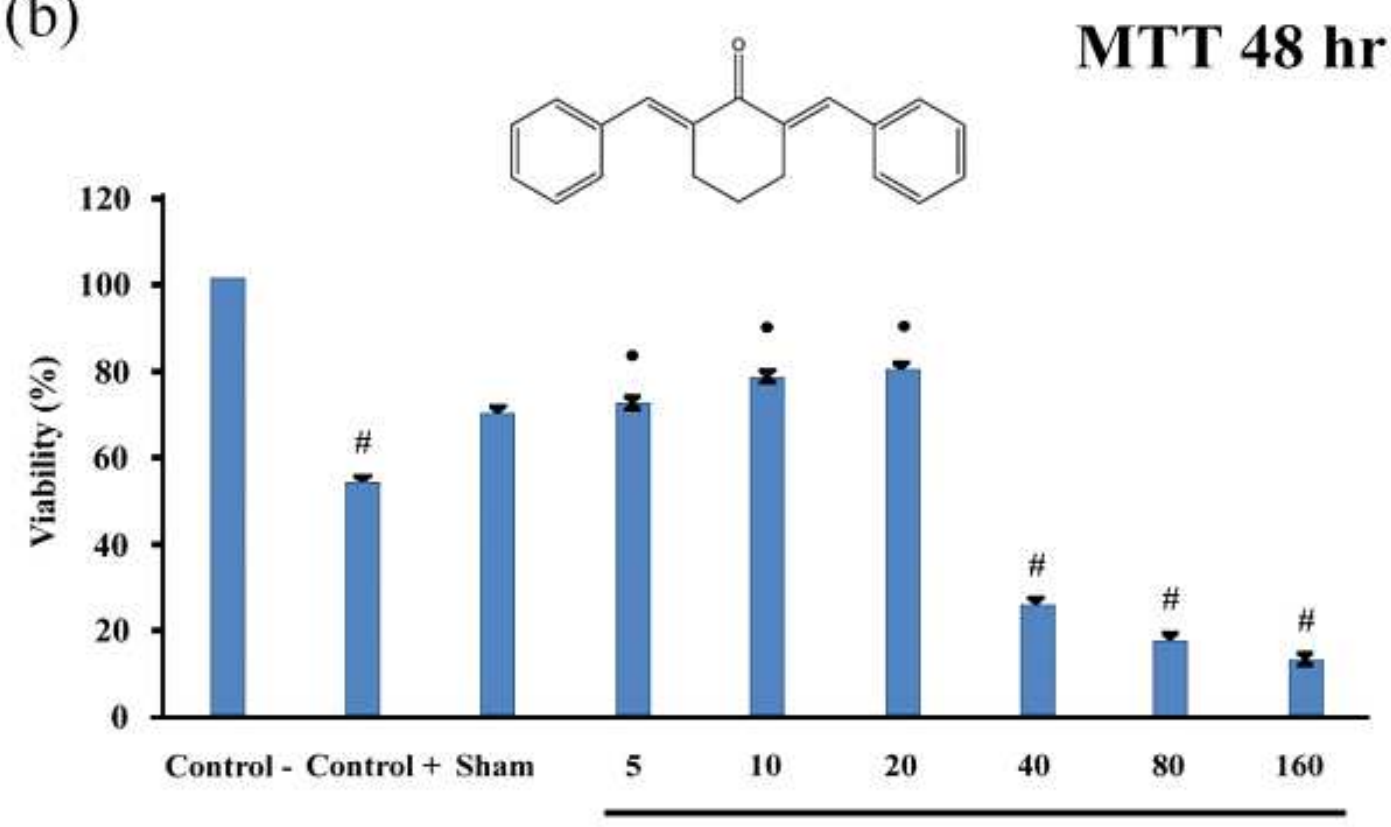

Chalcone $1(\mu \mathrm{g} / \mathrm{ml})$

\section{Figure 4}

Viability percentage of PC12 cells treated with different concentrations of Chalcone 1 after (a) 24 and (b) 48 hour. \# Significant difference with the negative control group at the same time $(p<0.01)$. * Significant difference with the positive control group at the same time $(p<0.01)$ 
(a)

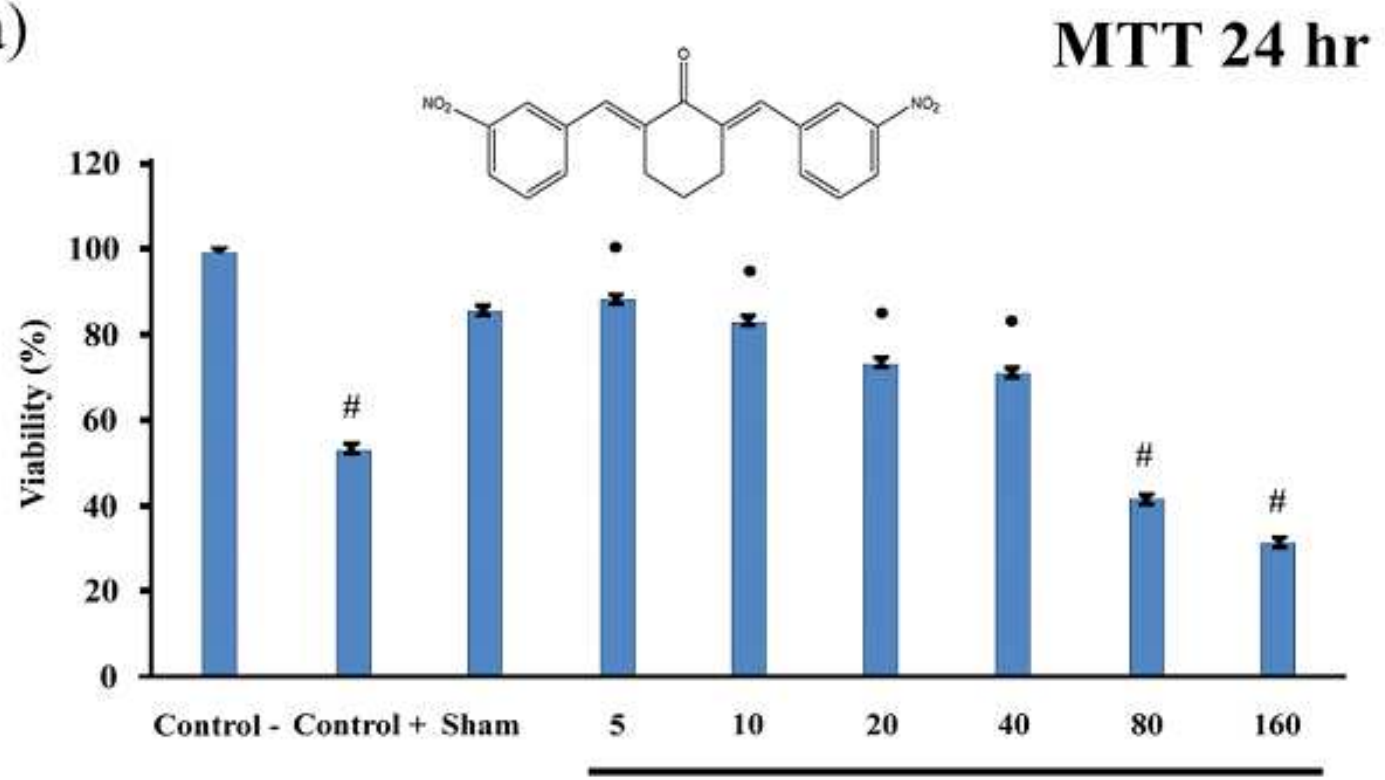

Chalcone $2(\mu \mathrm{g} / \mathrm{ml})$

(b)

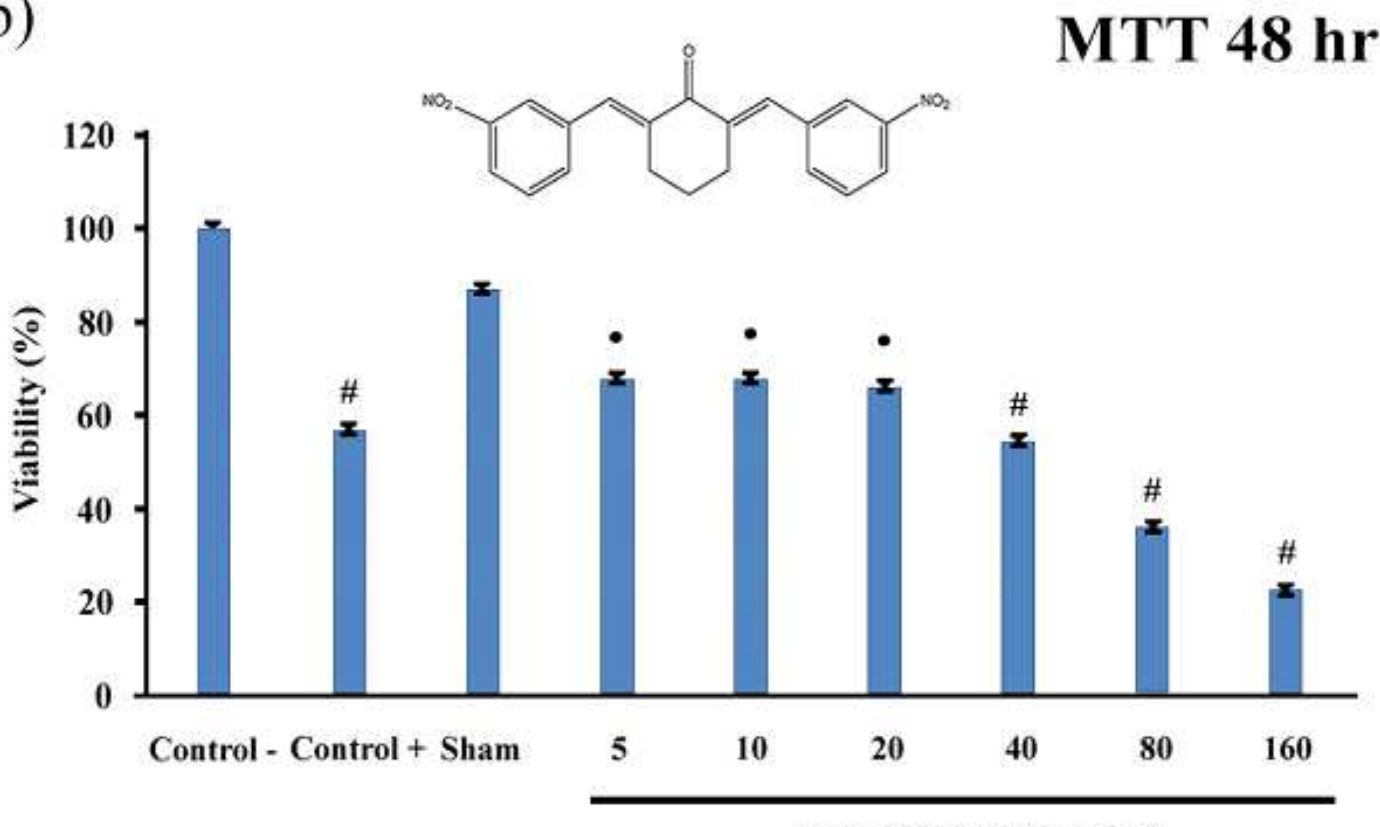

Chalcone $2(\mu \mathrm{g} / \mathrm{ml})$

\section{Figure 5}

Viability percentage of PC12 cells treated with different concentrations of Chalcone 2 after (a) 24 and (b) 48 hour. \# Significant difference with the negative control group at the same time $(p<0.01)$. Significant difference with positive control group at the same time $(p<0.01)$ 
(a)

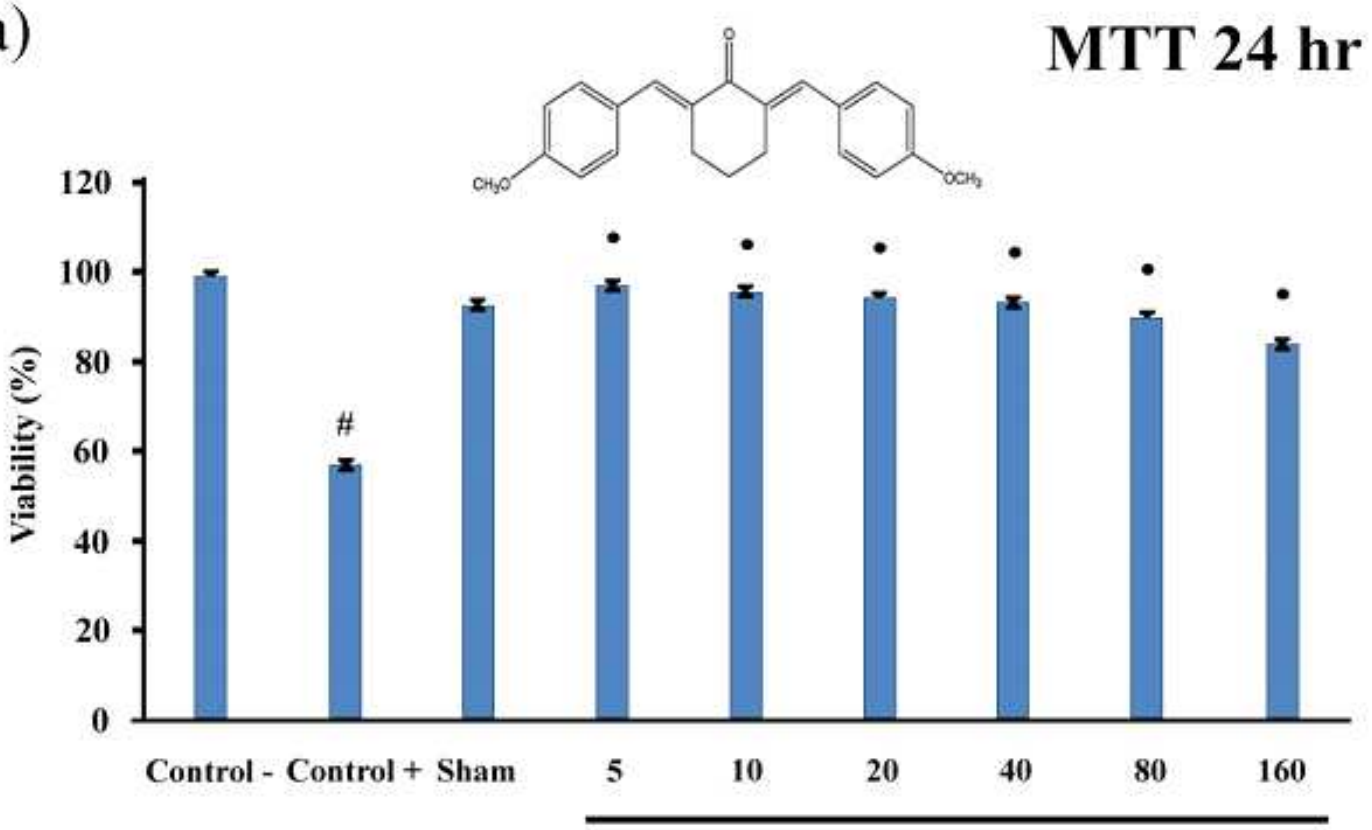

Chalcone $3(\mu \mathrm{g} / \mathrm{ml})$

(b)

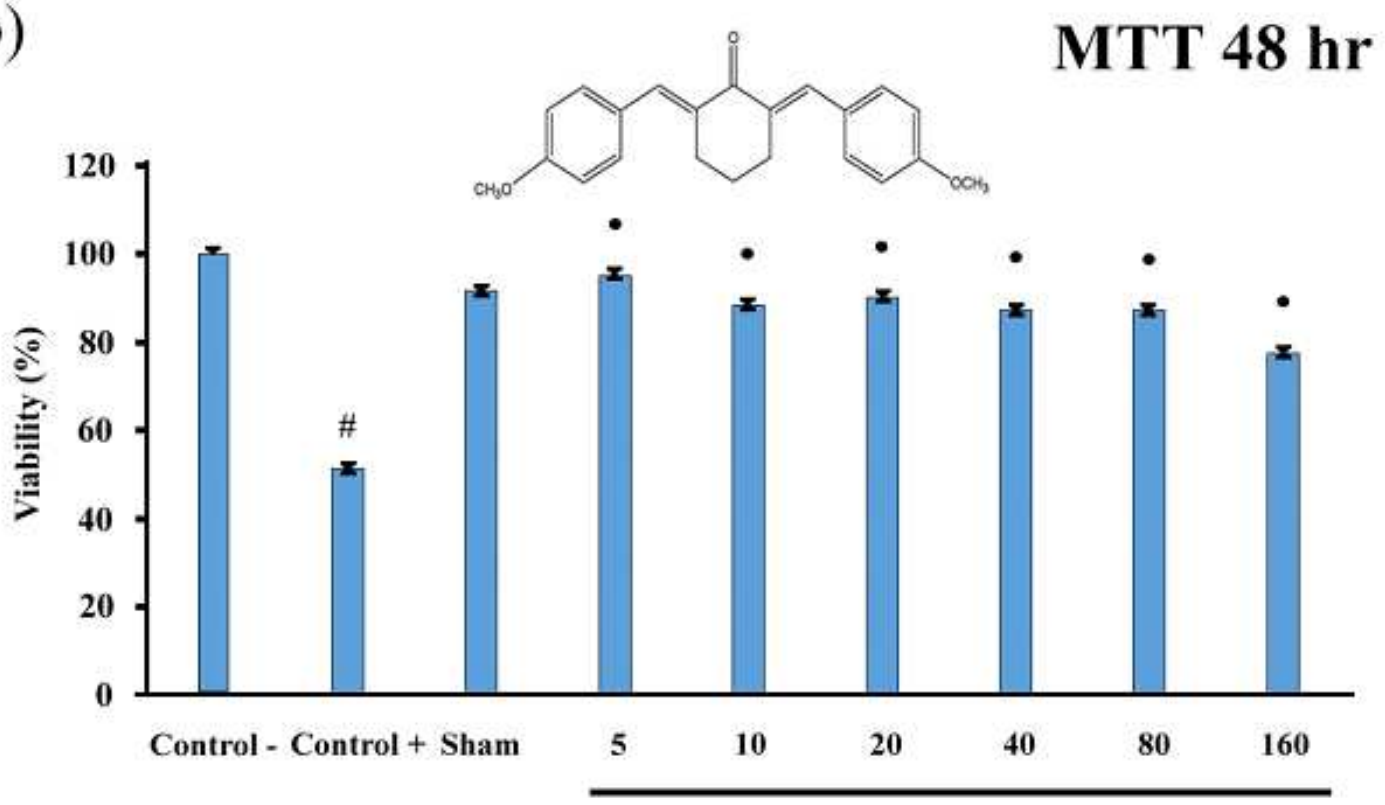

Chalcone $3(\mu \mathrm{g} / \mathrm{ml})$

\section{Figure 6}

Viability percentage of PC12 cells treated with different concentrations of Chalcone 3 after (a) 24 and (b) 48 hours. \# Significant difference with the negative control group at the same time $(p<0.01)$. Significant difference with the positive control group at the same time. $(P<0.01)$ 


\section{6-OHDA $(75 \mu \mathrm{M})$}

Chalcone 1

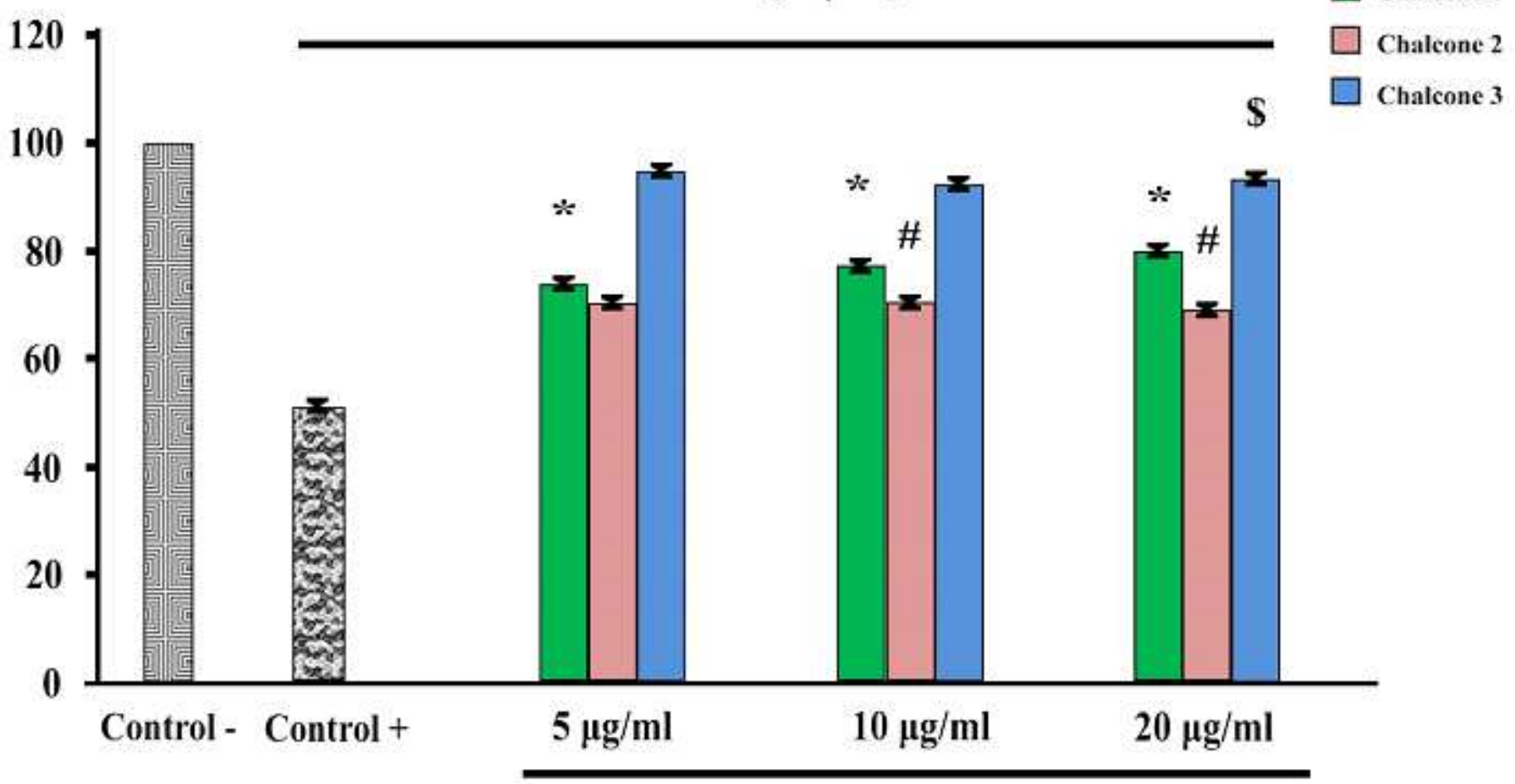

\section{Chalcone}

Figure 7

Comparison of the viability of Chalcones 1,2 , and 3 for 48 hours \# significant difference with the negative control group at the same time $(p<0.01)$. Significant difference with the positive control group at the same time $(p<0.01)$ 


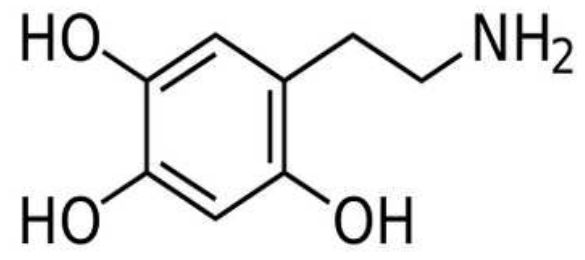

(a) 6- hydroxyl-dopamine

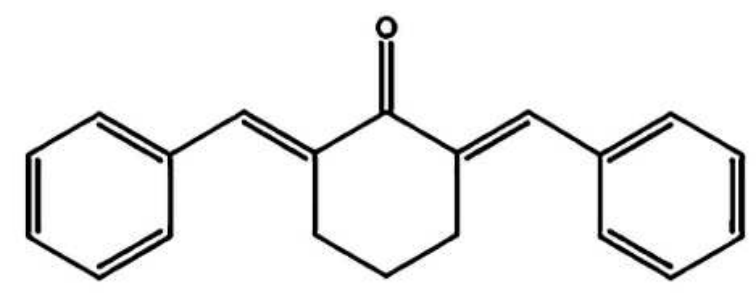

(b) 2,6-Dibenzylidene-cyclohexanone

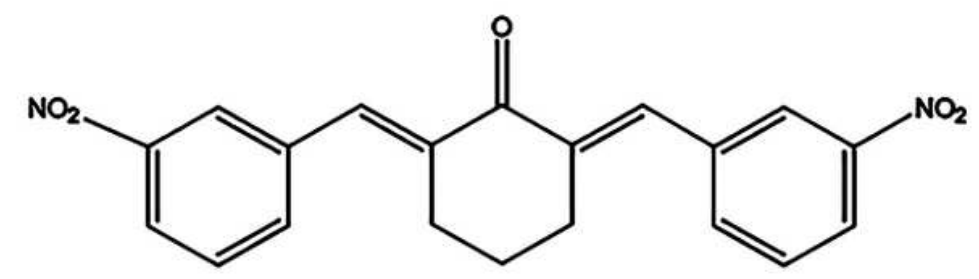

(c) 2,6-Bis-(3-nitro-benzylidene)-cyclohexanone

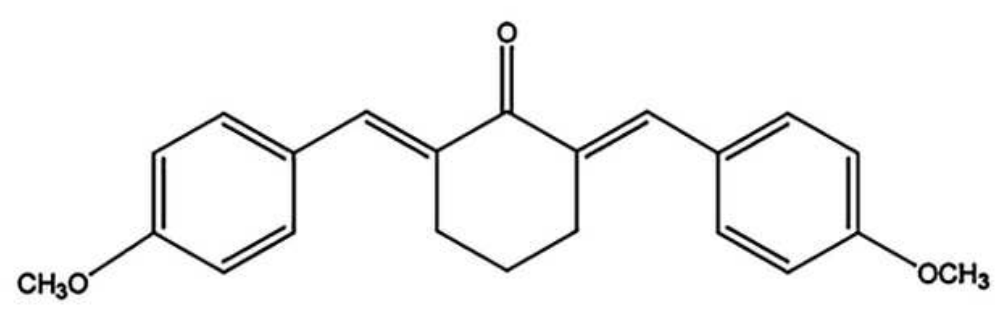

(d) 2,6-Bis-(4-methoxy-benzylidene)-cyclohexanone

\section{Figure 8}

Chemical structures of (a) 6-OHDA, (b) Chalcone 1, (c) Chalcone 2, (d) Chalcone 3.

\section{Supplementary Files}

This is a list of supplementary files associated with this preprint. Click to download.

- SupplementaryInformationSR.docx

- GraphicalAbstractSRSh.Golghasemi.docx 